\title{
Os Cadernos do Nosso Tempo e o Interesse Nacional
}

\section{Cristina Buarque de Hollanda}

Professora adjunta do Departamento de Ciência Política da Universidade Federal do Rio de Janeiro (UFRJ). E-mail: cristinabuarque@gmail.com

\section{INTRODUÇÃO}

E m princípio dos anos 30, os intelectuais dedicados à formação do campo das Ciências Sociais no Brasil buscaram diferenciar suas agendas de investigação daquelas da História, da Geografia, do Direito e da Educação, áreas do conhecimento que já tinham, à época, contornos disciplinares mais nítidos. Inscritos na zona de fronteira destas disciplinas, buscaram modos próprios para estudar a sociedade e a política.

Este esforço de distinção foi combinado à crítica da imaginação livre na forma de ensaio social e político. No lugar do devaneio retórico, alheio à reflexão sistemática sobre a cena nacional, os novos cientistas propunham a disciplina do exercício intelectual. A criação da Escola Livre de Sociologia e Política de São Paulo (ELSP), em 1933, e a fundação da Universidade de São Paulo (USP), em 1934, foram eventos inaugurais dessa nova postura reflexiva. Se não iniciaram o critério científico para tratar temas sociais e políticos, deram feição institucional a ele. No Rio de Janeiro, a Universidade do Distrito Federal (UDF), que teve vida breve entre 1935 e 1939, e a Faculdade Nacional de Filosofia (FNFi), criada em 1939, também tomaram parte do processo de instalação das Ciências Sociais no país. Para lidar com a incipiência do novo campo de estudos e alinhá-lo aos padrões do trabalho científico, um segmento

DADOS - Revista de Ciências Sociais, Rio de Janeiro, vol. 55, nº3, 2012, pp. 607 a 640. 
expressivo de professores estrangeiros foi incorporado aos quadros universitários. Entre eles, Donald Pierson, Jacques Lambert, Roger Bastide, Claude Lévi-Strauss e Radcliffe-Brown.

O processo de formação das novas redes intelectuais não foi destituído de tensão e também mobilizou autores fora da Universidade, organizados em institutos de pesquisa autônomos. Nos anos 50, ganhou volume a querela entre cariocas e paulistas em torno da definição dos termos científicos para lidar com a sociedade e a política, objetos volúveis e sem fixidez aparente. De um lado, os intelectuais do Rio de Janeiro, movidos por paradigma de autenticidade, reconheciam como científica a reflexão sobre realidade nacional imune a modelos estrangeiros e inoportunos de metodologia e análise. A reflexão autêntica sobre a sociedade era percebida como instrumento para agir sobre ela. De outro lado, pensadores paulistas reivindicavam para si maior acuidade no trato científico, sem pudores em incrementar o debate sobre questões nacionais com instrumentos teóricos estrangeiros. Nesta perspectiva, a reflexão imediatamente dirigida à prática tendia ao estigma de ideologia. Essas identidades intelectuais ganhavam definições mais nítidas na medida da recusa mútua. Isto é, cariocas faziam-se mais cariocas na medida em que se percebiam como não paulistas, e vice-versa. A oposição rígida entre intelectuais engajados e colonizados, de acordo com a taxonomia carioca, e entre ideólogos e verdadeiros cientistas, conforme designação paulista, tende, contudo, a negligenciar as importantes zonas de confluência entre estes operadores intelectuais.

Apesar de uma clivagem de fato no entendimento sobre métodos e fins do exercício intelectual, cariocas não foram imunes à sistematização da reflexão sobre realidade e paulistas não se fizeram insensíveis ao objetivo de transformá-la. Os dois grupos pareceram compartilhar, de modos variados, os objetivos de entendimento e transformação do real.

Longe de recensear os termos do desacordo em tela, o objetivo deste artigo é lançar luz sobre uma das peças deste cenário de disputa, um capítulo importante e inexplorado da experiência intelectual carioca nos anos 50. A partir das cinco edições dos Cadernos do Nosso Tempo, publicados entre os anos de 1953 e $1956^{1}$, investigarei o idioma nacionalista ${ }^{2}$ de seus autores-editores, reunidos no Instituto Brasileiro de Economia, Sociologia e Política (IBESP) ${ }^{3}$, sob a liderança de Hélio Jaguaribe. Para Simon Schwartzman, ali estava contida, "no nascedouro, toda a 
ideologia do nacionalismo" (Schwartzman, s.d:4). Por meio dos Cadernos, estes intelectuais buscavam esclarecer o estado da arte da política no país, cogitavam sobre modos de agir dos diferentes segmentos da sociedade e tinham a intenção de induzir e ajustar seu movimento.

No campo do pensamento social e político brasileiro, o IBESP permaneceu à sombra do Instituto Superior de Estudos Brasileiros (ISEB), modelo mais acabado do seu projeto político original. Embora aquém da fórmula pública imaginada por Jaguaribe, o ISEB alcançou vinculação ao Estado, por meio do Ministério da Educação e Cultura, e destacou-se na cena política e editorial nacional. O IBESP e os Cadernos, que viveram um período de superposição com o ISEB ${ }^{4}$, mereceram inúmeras (e esclarecedoras) referências em estudos direcionados, parcial ou integralmente, para a investigação da sua forma posterior (entre eles, Abreu, 1979; Pécaut, 1989; Jaguaribe, 1979; Ferreira, 2001). Em grande medida, portanto, o IBESP foi recuperado como contexto do ISEB, e não como objeto de estudo em si.

A mais importante exceção a esta condição marginal na bibliografia é uma breve e valiosa introdução de Simon Schwartzman a volume com artigos selecionados dos Cadernos $^{5}$. Nela, o autor se dedica à tese de excepcionalidade da experiência intelectual do IBESP, "responsável por uma série de ingredientes que teriam presença duradoura no ambiente político brasileiro" (Schwartzman, s.d:6).

Além deste texto de inspiração exclusiva, os Cadernos foram recuperados por referências a artigos isolados, como "O Inconsciente Sociológico", de Guerreiro Ramos (1956), e "A Crise Brasileira", de Hélio Jaguaribe (1953), marcos na biografia intelectual destes autores, casos em que o protagonismo autoral ofuscou a cena editorial.

Por fim, vale ainda notar a presença dos Cadernos em estudos sobre o populismo. Ao tratar das primeiras formulações sobre o tema no Brasil, Ângela de Castro Gomes (2001) destaca o ensaio “O que é o Ademarismo?", publicado no segundo número do periódico. Neste texto, o autor não identificado ${ }^{6}$ debruça-se sobre um fenômeno político cuja substância é produzida pelo líder, e não pelo partido, ao contrário da experiência então corrente de políticos do Partido Social Democrático, quase exclusivamente sustentados por rede de clientela rural já estabelecida. Embora não prescinda do partido, o ademarismo autonomiza-se dele em medida significativa. Segundo Gomes, o artigo em tela teria inaugurado um tema e um enfoque que não mais abandonariam o 
"horizonte de formulações" das Ciências Sociais no Brasil. A associação entre as condições de vazio de liderança da classe dirigente, inconsciência do trabalhador a respeito da sua situação de classe e surgimento fortuito de líder populista ganharam "longa carreira" nos estudos sobre populismo (Gomes, 2001:24). Nos mesmos termos da autora, também Jorge Ferreira recupera o tratamento dos Cadernos ao ademarismo (Ferreira, 2001:67-68).

Tendo em vista a escassez e a orientação sobretudo temática dos estudos sobre os Cadernos, este artigo é dedicado a uma mirada abrangente e sistemática do projeto editorial do IBESP. A partir da categoria nativa do interesse nacional, que implica os grandes temas do Instituto, buscarei delinear os termos do projeto político ibespiano.

A organização dos Cadernos não seguiu padrão rígido. Apesar disso, contou com um núcleo de edição permanente, constituído por um texto enxuto de apresentação, uma seção intitulada "noticiário do IBESP" e textos variados sobre as cenas nacional e internacional. As flutuações de cada edição incluíram notas de pesquisa, informes, estudos, entrevistas e transcrição de documentos.

Os autores-editores dos Cadernos, elencados no conselho de redação da revista a cada número, compunham um grupo razoavelmente estável e enxuto $^{7}$. Eles não se pautavam por um paradigma autoral pronunciado. Ao final de cada volume, na seção do índice, apenas as iniciais dos autores (cujos nomes completos podem ser deduzidos da consulta aos membros do conselho) figuram ao lado dos textos. Em muitos artigos simplesmente não há referência de autoria ${ }^{8}$.

A despeito da variedade de autores, os artigos são bastante afinados entre si, tanto na definição quanto no tratamento dos temas, e não apresentam marcas distintivas, à exceção dos textos de Guerreiro Ramos e Hélio Jaguaribe. A proposição de categorias autorais para descrição da realidade brasileira - como o Estado Cartorial, de Jaguaribe (autor não identificado, 1956b) ${ }^{9}$, ou a jeunésse dorée, de Ramos (1955a) - não destoa, entretanto, do perfil analítico mais geral dos Cadernos. Apesar de, conforme Schwartzman, os colaboradores dos Cadernos não terem uma "maneira unívoca e coerente de ver as coisas" (Schwartzman, s.d:3), há significativa convergência interpretativa entre os artigos que compõem os cinco números sob investigação. As diferenças eventuais não carregam tintas fortes. Autores e indivíduos diluem-se em projeto coletivo, dedicado à análise e à reforma das condições de vida no país. 
Embora seja razoável supor que a ascendência intelectual de Jaguaribe sobre o grupo tenha influenciado o tom da afinidade de temas e argumentos, a adesão a um sentido comum da política foi a peça-chave desta agregação.

O editorial do primeiro número esclarece que o conteúdo dos Cadernos não nasce de exercícios solitários de reflexão, mas de uma rotina de debates em torno dos problemas "do nosso tempo e do Brasil" (autor não identificado, 1953:1). A forte identidade intelectual em torno da questão nacional produz importante harmonização do dissenso e dissipação dos protagonismos individuais. As leves fissuras evoluirão para querelas de fôlego apenas depois da conversão do IBESP em ISEB. Por ora, a influência de Hélio Jaguaribe sobre o grupo ainda não fora ameaçada pelas investidas ultranacionalistas de Guerreiro Ramos ${ }^{10}$.

Entre os autores dos Cadernos, a proximidade de diagnósticos e prognósticos para a cena nacional combinava-se a um forte sentido de responsabilidade social. Eles atribuíam a si e a extratos progressistas - ou potencialmente progressistas - da sociedade um papel fundamental na condução da política nacional por bons rumos. Na sua avaliação, embora alguns sinais de progresso figurassem no horizonte, a superação do atraso não viria de um movimento espontâneo. Se legada a si própria nas condições que então se verificavam, a sociedade brasileira, cindida em interesses antagônicos, tenderia a reproduzir indefinidamente as condições do seu infortúnio.

Era preciso prever operadores da transformação. Os intelectuais deveriam figurar neste elenco como agentes de conscientização. Schwartzman chega a identificar um sentido "radicalmente novo" nesta responsabilidade autoatribuída dos ibespianos: "pela primeira vez", um grupo de intelectuais "se propõe a assumir uma liderança política nacional por seus próprios meios" (Schwartzman, s.d.:4). Em desacordo com ele, Pécaut descarta a excepcionalidade do empreendimento, mas sublinha a marcada disposição do grupo em se "associar à direção dos negócios públicos" (1989:96) e iluminar as forças do progresso ${ }^{11}$.

Nos Cadernos, portanto, a busca de entendimento sobre o estado da arte da sociedade e da política tem estreita imbricação com a imaginação dos meios e dos fins da sua transformação. A reflexão sobre o que foi, o que é, o que deve ser e como deve passar a ser a política constitui uma teia argumentativa indissociável. Isto é, o entendimento sobre cada um desses níveis não pode prescindir da consideração dos demais. 
Além da imaginação de futuro condicionada ao diagnóstico dos tempos passado e presente, condizente com um princípio lógico-temporal linear, a retórica dos Cadernos também opera com a sequência invertida, isto é, o que foi e o que é também podem ser mais bem entendidos em vista do horizonte normativo (de meios e fins) que se tem em vista. $\mathrm{O}$ paradigma da colonização, por exemplo, deve ser mais elucidativo sobre o passado do país na medida em que a compreensão do seu perfeito avesso, o paradigma da autonomia, informa sobre a expectativa de futuro.

Neste artigo, a recuperação dos argumentos-chave dos Cadernos transitará, portanto, entre interpretação e deontologia. Em vista do desconhecimento sobre a autoria de parte significativa dos documentos sob investigação e do forte sentido de obra coletiva já mencionado, a organização deste artigo seguirá percurso temático. O objetivo de sistematização não escapará, entretanto, à marcada circularidade de discurso dos artigos em tela. Análise e normatividade implicam-se reciprocamente nos ensaios para "esclarecimento da opinião pública a respeito da atual situação política do país" (autor não identificado, 1956b:189). O esforço de reconstituição não escapará a este emaranhado.

A primeira seção do artigo, dedicada ao diagnóstico dos Cadernos sobre a situação política do Brasil, antecipará fragmentos da imaginação de futuro para o país, tema da seção seguinte. A investigação das condições da nação no tempo presente combina história e sociologia. Nesta seção inaugural, delineiam-se os termos do conflito insuperável entre atraso e progresso, dicotomia que esclarece a experiência política e social do passado e alcança expressão flagrante na disposição sociológica contemporânea. A exposição sobre as três fases da formação nacional (colonialismo, semicolonialismo e autonomia econômico-social) combina-se às narrativas sobre a cisão entre classes e as características do interesse nacional.

A segunda seção trata da fórmula dos Cadernos para a superação dos entraves ao progresso nacional. O tom geral é de otimismo diante da expectativa de um futuro sem amarras do passado. O curso natural da história, que deveria vir precipitado na fase contemporânea por intelectuais e segmentos sociais progressistas, apontava para um cenário de harmonização das relações em torno de um único interesse compartilhado: o interesse nacional. Apesar da expectativa positiva quanto ao amadurecimento de uma condição autônoma para a nação, o aprofun- 
damento do atraso figura como hipótese lógica, no caso das classes que devem conduzir a sociedade ao futuro virtuoso negligenciarem seu papel histórico.

A seção seguinte é então voltada para a interpretação dos autores dos Cadernos sobre os obstáculos ao progresso. Em linhas gerais, os operadores de inconsciência, de qualidades e relevâncias diferenciadas, e estreitamente vinculados entre si, são três: o vício internacionalista de comunistas e udenistas, o conservadorismo da classe média conservadora e o populismo ademarista.

Por fim, a última seção deste artigo, sem escapar ao eixo temático proposto, tem uma marcação cronológica. Nela, me ocupo do quinto número dos Cadernos, publicado em março de 1956, no qual se observa inflexão significativa no discurso, sem prejuízo do círculo argumentativo entre análise e norma.

Editados em período agônico da democracia recém-instituída, os Cadernos testemunharam a grave crise política que culminou no suicídio de Getúlio Vargas e também os sucessivos arranjos de poder para lidar com sua presença ausente na política. A saída repentina de Vargas da cena política não instituiu ruptura nas interpretações e prognósticos dos Cadernos, mas importante ajuste. O evento histórico inesperado teria tido o efeito de maturação da consciência média a respeito da condição nacional. Sem considerar méritos ou deméritos do governo extinto, os autores-editores dos Cadernos interpretam a reação conservadora a ele como movimento quiçá derradeiro das forças do atraso e, em seguida, a reação ao reacionarismo como sinal de vitalidade de segmentos da sociedade que, até então, seguiam inertes e alheios ao interesse nacional.

O último volume dos Cadernos investiga, entre outros, o legado político de Vargas e a metamorfose política do getulismo. Superada a vigência do getulismo histórico, personalista, percebia-se a instalação do getulismo ideológico, nacionalista, que configurava um caminho possível para o progresso desejado. Neste novo contexto, Partido Social Democrático (PSD) e Partido Trabalhista Brasileiro (PTB) deixavam de ser imagem-síntese do artificialismo partidário e ganhavam contornos políticos mais nítidos. De emulação da figura pessoal de Vargas passavam a ser legendas com alguma consistência e representatividade. O cenário partidário nacional parecia enfim transitar da condição amorfa que o 
tornava refém dos segmentos conservadores da sociedade para uma situação mais compatível com o paradigma de autonomia política.

A ideia e a materialidade do progresso não instituem, entretanto, um percurso linear na narrativa dos Cadernos. O atraso e a crise seguem como contraface do discurso e encerram teimosa e temerosa potencialidade. Nesta cena encruzilhada, evidencia-se a urgência do nacionalismo em suas versões política e sociológica. Isto é, o anseio "por uma certa racionalização do aparelho estatal", nos termos de Pécaut (1989:95), combina-se ao objetivo das consciências de classe, que se harmonizam na adesão comum ao progresso nacional. Nesta perspectiva, a política é esvaziada de conflito e movida pela suposta afinidade de propósitos entre os variados segmentos da sociedade. Os autores-editores do IBESP percebem a si próprios e aos intelectuais em geral como elementos centrais de maturação da cena institucional e também da consciência mais geral sobre o interesse comum. Os Cadernos, seu principal veículo de comunicação, são objeto, portanto, de marcada expectativa política.

\section{DIAGNÓSTICO DA CRISE NACIONAL: PARADIGMAS HISTÓRICO E SOCIOLÓGICO}

Parte significativa do esforço interpretativo dos Cadernos está voltada para os contornos históricos e sociológicos da crise política nacional. Já na primeira edição do periódico, vem publicada "A Crise Brasileira", de Hélio Jaguaribe. Neste artigo, o autor narra o legado colonial no tempo presente: o paradigma espoliador, que sobreviveu à "expansão da economia urbana, ao crescimento demográfico e à industrialização". O povo não teria alcançado "espírito de iniciativa" e a circulação de elites cumpria ritmo lento, apesar do golpe ao clientelismo representado pelo ingresso das massas na política, com o Estado Novo de Getúlio Vargas. Refém de "crenças arcaicas" e esvaziado de "autênticos estímulos para uma reação original", o pensamento brasileiro seguia "desabituado de reflexão própria" (Jaguaribe, 1953c:128-129). O diagnóstico dos tempos passado e presente repercutiam na imaginação de futuro. Não era possível, afinal, esperar autonomia de um povo destituído de movimento, refém da circunstância política.

Nesta mesma linha de argumentação, o autor não identificado de estudo intitulado "Para uma Política Nacional de Desenvolvimento" (1956b), publicado na quinta edição da revista, identifica três capítulos 
de formação da nação. O primeiro deles, do colonialismo, pautou-se em economia de produção escravocrata e sobreviveu até meados do século XIX. Neste momento original, argumenta o autor, a comunidade nacional organizou-se a serviço da metrópole e teve seu desenvolvimento estritamente condicionado por impulsos exógenos. Experimentou-se naquele tempo longo a forma limite da dependência. Sendo uma "peça da economia europeia", o país não gozou de "existência própria" (autor não identificado, 1956b:70). O colonialismo, portanto, foi um tempo fora do tempo, destituído de movimento e impregnado de um sentido estático, avesso ao princípio da política. Em franco contraste, as sociedades europeias experimentaram o tempo com densidade: nos séculos XV e XVI, atravessaram o Renascimento; no XVII, o Barroco; no XVIII, a Ilustração e, enfim, na primeira metade do XIX, a Revolução Industrial. Sua economia transitou do mercantilismo ao industrialismo.

Abolido o tráfico de escravos, o Brasil teria ingressado em fase semicolonialista, intermediária entre o colonialismo original e a autonomia econômico-social. Trata-se do segundo capítulo da narrativa em tela sobre a história do país. Nela, o país combinava permanências da situação anterior, como a forte vinculação da produção a demandas externas de consumo, e novidades que apontavam em direção à superação da condição de dependência. Entre elas, a formação de uma reserva nacional de mão de obra. O período em questão estende-se até a crise do café em 1930, que combinou o auge da política de acumulação dos excedentes não exportados de café ao colapso da economia mundial em 1929.

Os anos 30 teriam inaugurado, por fim, a passagem para um momento mais avançado da transição em direção à autonomia nacional. Eles representam a terceira fase da cronologia proposta, que constitui pano de fundo histórico dos Cadernos de um modo geral. No novo cenário, cidades e indústrias retroalimentam-se. A expansão do mercado interno associada ao fenômeno da urbanização seria, ao mesmo tempo, origem e efeito da nova realidade industrial no país, impulsionada pela longa permanência de Vargas na Presidência da República e pelos desdobramentos da Segunda Guerra Mundial na economia nacional: a necessidade de substituição das importações. O contraste com a situação anterior de dependência era notável. 
A despeito disso, ainda persistiam entraves ao pleno desenvolvimento, vinculados ao regime semicolonialista. O progresso observado era tímido, se comparado a suas potencialidades. A indústria nacional ainda dependia da importação de bens de produção e matérias-primas. Além disso, o país encontrava-se em "estágio rudimentar" na produção de energia, apresentava "tendência regressiva dos transportes ferroviário e marítimo" (autor não identificado, 1956b:85) e, por fim, estava abatido por um processo inflacionário alarmante, resultado da insuficiência da oferta de gêneros em relação à procura - isto é, da impossibilidade da produção nacional atender à demanda do mercado nacional em franca expansão. Diante deste cenário, a querela em curso entre inflacionistas (que "pretendem manter as condições em que o desenvolvimento vem se processando") e deflacionistas (que "pretendem sustar ou reduzir o desenvolvimento econômico") seria inócua, pois não alcançava o cerne da crise: a "estrutura-tipo" do desenvolvimento verificado (Autor não identificado, 1956b:90).

Ainda sobre os contornos da crise, Oscar Lorenzo Fernandez, em "Análise Existencial da Realidade Brasileira" (Fernandez, 1955), publicado na quarta edição dos Cadernos, trata de características "físico-biológicos, sócio-históricos e culturais" da nação. Entre os limites naturais, elenca a escassa integração por rios e a baixa qualidade das terras, ofuscada durante séculos pelo otimismo que a floresta tropical produziu. A respeito da constituição psicológica - e por derivação sociológica - da nação, trata do que seriam legados viciosos de origem lusitana. Na sua fala, o "espírito de aventura" português constituiu "gosto pelo improviso e pelo precário", orientado por "postura parasitária exploradora" com relação ao Brasil. O país herdou o "satelitismo" de Portugal, agravado pela condição colonial. A partir do século XIX verificaram-se, contudo, "pruridos de diferenciação do campo criador", sintetizados pelo fenômeno Mauá, "incompreendido pela sociedade da sua época".

Por fim, Fernandez prolongou ainda a narrativa dos vícios lusitanos ao considerar a formação cultural brasileira. A nação padecia de graves "debilidade", "apatia do coletivo" e "insolidarismo". Não à toa, a iniciativa política em momentos-chave da história nacional - Independência, Abolição e República - concentrou-se no Estado. Índios e negros teriam se adaptado a "funções de interesse português", compondo o cenário de incompatibilidade entre as estruturas e suas "finalidades expressas". (Fernandez, 1955:152). 
A crítica contundente do autor, para surpresa do leitor, não conduz, entretanto, à suposição de perpetuação do infortúnio. De modo súbito e sem elucidar os caminhos, o autor anuncia a possibilidade de a nação renunciar à condição de objeto e fazer-se sujeito da sua história. $\mathrm{O}$ artigo se afina com o tom mais geral dos Cadernos na identificação de um tempo encruzilhada (que pode ter bom ou mau desdobramento), embora destoe dele na digressão sobre a condição lusitana ${ }^{12}$. Como os demais autores, Fernandez contorna, afinal, as fórmulas essencialistas, avessas ao movimento, e faz prevalecer o protagonismo das circunstâncias, móveis.

Para os autores-editores dos Cadernos, é justamente a realidade - e também a expectativa - do movimento que estão na origem da dúvida sobre o futuro. O progresso inaugurado nos anos 30, se legado a si próprio, poderia estancar ou mesmo retroagir. No panorama sociológico em evidência, a possibilidade do retrocesso era representada pelos segmentos da sociedade que extraíam benefícios do atraso, isto é, pelos latifundiários, pela burguesia comercial e pela classe média parasitária, alocada em postos públicos e desinteressada na eficiência do Estado. Associados a um modelo anacrônico, baseado na exportação de matéria-prima e na importação de bens manufaturados, eram um legado vicioso em sociedade que transitava para condição industrial. Estes setores fixaram vínculos com o modelo da dependência e projetavam o passado no futuro. A condição de sintonia com a vida moderna era, portanto, a transformação do horizonte econômico.

No novo paradigma, as "velhas oligarquias latifúndio-mercantis" deviam converter-se em "classe de modernos agricultores e de eficientes homens de negócio". Para tanto, no lugar de explorarem a escassez e beneficiarem-se da "sub-remuneração do trabalho", deveriam ser capazes de produzir "lucro técnico, auferido mediante a crescente redução dos custos, através da adoção de processos tecnológicos mais avançados e de formas mais eficientes de organização do trabalho" (autor não identificado, 1956b:126).

Na prática, para os ibespianos, a experiência estática destes grupos, imunes à modernização, contrastou com a vitalidade potencial - embora escassamente manifesta - da burguesia industrial, do operariado urbano e dos setores progressistas da classe média. Apesar de associados à virada recente em direção a um modelo econômico autônomo, esses segmentos progressistas não teriam alcançado consciência de sua 
posição estratégica no processo social em curso. De acordo com a interpretação marxista, ainda não haviam transitado da condição de classe em si para classe para si. Movida por interesses mal compreendidos, a burguesia industrial não assumira a liderança do novo tempo econômico e político. Junto aos trabalhadores e aos técnicos e administradores de classe média, a fração moderna da burguesia faria jus ao protagonismo da cena política, mas ocupava de fato um lugar coadjuvante, ofuscada pelo espectro anacrônico do agrarismo irrefletido.

A importância política dos segmentos vinculados a novas formas e relações de produção estaria aquém de sua relevância econômica e social. A penas a inflexão nacionalista poderia corrigir este equívoco e ajustar o desempenho real da burguesia industrial e segmentos adjacentes a suas potencialidades. Tendo em vista um forte sentido de convergência e coesão na política, esta metamorfose não se faria em detrimento das classes com aspecto e atuação passadistas. À diferença do paradigma colonial, de espoliação e dependência, a virada em direção ao progresso, harmonizada pelo interesse nacional, teria fundamento integrador. Todos os segmentos da sociedade teriam lugar nela.

Entre os intelectuais dos Cadernos, o contraste entre as leituras sobre passado e presente, de um lado, e a projeção de futuro, de outro, é bem ilustrado pelas imagens de divisão e unidade. Na sua perspectiva, a consolidação do moderno não está contida na inversão de protagonismos e em um novo arranjo de poder. O sentido radical de novidade na política implica - mas não se esgota - nas mudanças de forma. Há também - e fundamentalmente - um deslocamento substantivo das diferenças: elas deixam de conviver com base num princípio de oposição e transitam para um regime de complementaridade. Integração e unidade são o fundamento da imaginação sociológica e política dos intelectuais em vista. O sentido de conflito figura apenas no curto prazo, como motor de superação do equívoco divisionista. A imaginação de futuro não acolhe interesses contrapostos.

\section{DEONTOLOGIA DOS CADERNOS: O NACIONALISMO BEM COMPREENDIDO}

A deontologia dos Cadernos gravita em torno da noção de interesse nacional. Nela está o fundamento da boa ideologia e também da resistência autêntica à querela comunismo-capitalismo. Nesta seção, apresento o modo como os autores-editores do IBESP, por meio da via naciona- 
lista, buscaram contornar a polarização do cenário internacional e flertaram com o latino-americanismo.

Um dos argumentos-chave de Hélio Jaguaribe e seus demais companheiros de IBESP é que, no Brasil, o falso antagonismo entre interesses agrícola-comerciais e industriais produziria fragilidade de consciência do interesse nacional. Para eles, a "convivência cooperativa de todas as classes", condição de superação do subdesenvolvimento, deveria apaziguar os eventuais conflitos de interesses e expectativas entre classes. Era preciso contornar os extremos socialista e capitalista. No horizonte imediato das relações sociais, não seria oportuno supor uma "suicida repartição da riqueza" nem, por outro lado, uma "injusta concentração de poder de consumo" nas classes proprietárias. Uma e outra produziriam ruído ao objetivo comum do desenvolvimento.

Na forma de lamento, os autores constatam que os níveis de consciência sobre o mínimo denominador comum dos interesses seriam variados e ainda insuficientes para iniciar o processo de uma "revolução pacífica" (autor não identificado, 1956b:126-127). É justamente sobre esta zona de inconsciência que deveriam atuar os intelectuais de vanguarda. Na teoria da ação política dos Cadernos, a ideologia é investida de "validade geral" e avessa à noção marxista de "racionalização de um egoísmo de classe ou grupo" e ao "caráter unilateral e faccioso" que daí deriva (Jaguaribe, 1979:105). Não há, nesta perspectiva, determinação do lugar social de origem, e tampouco dos métodos, dos agentes revolucionários. Basta que eles sejam locutores de um interesse que extrapole as fronteiras de classe, sem que isto implique no uso da violência. Na hipótese de as classes dirigentes encontrarem-se "em relação estruturalmente disfuncional" com as massas, estas precisarão superá-las (ibidem:106). Se, entretanto, houver coincidência entre seus interesses situacionais e os do conjunto do país, estão dadas as condições para uma cooperação de classes, sem que isso implique na anulação da tensão entre elas. Os dissensos não chegariam a configurar antagonismo, pois constituem característica marginal - e não essencial - das relações entre classes proprietárias e não proprietárias. Nesta perspectiva, é autêntica toda ideologia cujos fins ultrapassam as estreitas considerações de classe e cujos operadores são capazes de mobilizar atores exógenos a seu meio social imediato.

Segundo Schwartzman, os intelectuais do IBESP atribuem a si próprios "um papel muito mais importante" do que aquele que Karl Mannhe- 
im "havia pretendido para sua intelligentsia". A possibilidade de enxergar acima dos horizontes de classe seria, para eles, apenas um "passo inicial para as transformações sociais que o país exigia" (Schwartzman, s.d.:6).

A consciência privilegiada sobre o caso brasileiro resulta na proposta nacional-desenvolvimentista para o país, típica da primeira fase do ISEB, mas já com contornos nítidos nos Cadernos. Levando em conta o lugar-chave da burguesia nacional no processo de industrialização em curso, a despeito de sua ainda frágil consciência de classe, Jaguaribe e os intelectuais do IBESP a pontam sua vocação para consolidar a transição de uma sociedade agrária para uma sociedade moderna.

Neste percurso, a via nacionalista afirma-se como única alternativa autêntica à querela entre comunismo e capitalismo. A adesão eventual aos termos políticos do mundo cindido, tendo em vista o ímpeto imperialista das duas forças em disputa, lançaria a nação numa condição subordinada. Para Jaguaribe: "o certo é que a economia de espoliação será o resultado inevitável da conquista, pelos Estados Unidos ou pela Rússia, da hegemonia mundial. (...) Ante esta motivação, de nada adiantará a circunstância de os países mais fracos terem combatido a favor ou contra o vencedor" (Jaguaribe, 1953c:134).

Assim como China, Indonésia e "outros países latino-americanos", o Brasil teria a possibilidade de "destino histórico próprio". Para todas as grandes nações subdesenvolvidas, a via nacionalista seria uma posição de "oportuno realismo". Dessa forma, o verdadeiro interesse dos países em desenvolvimento seria a equiparação de forças entre o "imperialismo americano" e o "expansionismo soviético" (autor não identificado, 1956b:170-172), pois a hegemonia de uma ou outra parte instituiria maior tensão e dificuldade para a afirmação de novas nações autônomas. No caso brasileiro, o maior risco de "satelitismo" era em relação aos Estados Unidos. Para escapar aos riscos da subserviência, seria conveniente adensar relações com os países vizinhos.

A respeito da aproximação entre nações latino-americanas, versa o artigo intitulado "Denúncia João Neves" (autor não identificado, 1954b), publicado no segundo volume dos Cadernos. Nele, o autor recupera o episódio da denúncia de João Neves da Fontoura, ex-ministro do Exterior, contra o então presidente Vargas, acusado de alta traição com base em discurso atribuído a Juan Perón em dezembro de 1953. No referido discurso, cuja autenticidade nunca se confirmou, Perón teria relatado 
compromisso assumido por Vargas em torno da ativação do pacto ABC (Argentina, Brasil e Chile), originalmente firmado em 1915. Fontoura confirmava a intenção pan-americanista do presidente e alegava ter sido ele próprio, à frente da pasta do Exterior, o obstáculo à consecução desta ação que, se levada adiante, seria extremamente prejudicial aos interesses nacionais. $\mathrm{O}$ argumento do ex-ministro, endossado pela União Democrática Nacional (UDN), era que o integracionismo pretendido propiciaria condição hegemônica da Argentina na América Latina e também prejudicaria a "unidade das Américas".

Contra estes argumentos volta-se, de modo contundente, o autor do artigo. Para ele, não seria razoável supor o protagonismo argentino no cenário regional, tendo em vista a notória superioridade do Brasil com relação ao país vizinho. Quanto ao segundo eixo de argumentação, fundado na suposição de identidade das Américas, o autor descarta como ficcional. Para ele, o encontro geográfico de Brasil e Estados Unidos no continente americano seria "fortuito", obra do acaso. Nele habitam tipos inteiramente distintos de países: anglo-saxônicos e latinos. Haveria muito maior disparidade do que convergência entre eles, o que conduz à suposição de que "nem todas as formas de pan-americanismo são convenientes" (autor não identificado, 1954b:89).

Em sintonia com o paradigma da terceira via, o autor exorta a criação de uma "Comunidade de Defesa Latino-Americana", "destinada a evitar a guerra, a reduzir as pressões expansionistas e a fixar uma terceira posição, não comprometida com as outras duas" (autor não identificado, 1954b:93). Deste modo, o Brasil e as demais nações da América Latina escapariam aos rígidos modelos de organização da política em curso e esboçariam um modo próprio de situar-se no campo das relações internacionais. O latino-americanismo expandiria as possibilidades dos nacionalismos em jogo. A condição comum do subdesenvolvimento deveria servir como blindagem a todo mimetismo na política, vicioso por sua inespecificidade.

Para Hélio Jaguaribe, comunismo e capitalismo constituem modelos antitéticos apenas quando considerados artificialmente, em condição estática, destituída de movimento. Dado que a realidade é dinâmica, o desacordo essencial entre os dois inexiste: "considerados como processos sociais, o capitalismo e o socialismo se interpenetram, a despeito de seus modelos se excluírem mutuamente". Diz Jaguaribe não existir no mundo contemporâneo país em que se aplique o que possa ser reco- 
nhecido como "capitalismo puro". Para reforçar esta tese, parafraseia Schumpeter: "o regime da livre concorrência nunca se verificou em lugar algum". Em todas as nações teria se verificado "tendência crescente para a transferência do comando da produção da iniciativa particular para a iniciativa pública" (Jaguaribe, 1953c:148).

Na perspectiva proposta, o adensamento das funções estatais não é equivalente funcional do socialismo. O nacionalismo bem compreendido escapa à fixidez inócua e inverídica dos dois modelos em disputa e baseia-se no paradigma da conveniência, flanando com alguma liberdade em zonas de ação política e econômica tidas por antitéticas. Apenas o interesse nacional daria substância a uma boa síntese da política.

\section{OS TRÊS ISMOS DO ATRASO: MORALISMO, INTERNACIONALISMO E POPULISMO}

Estancada entre o atraso e o progresso, a nação poderia rumar em direção a um ou outro. Apesar da projeção otimista de futuro, uma espécie de pano de fundo do argumento dos Cadernos, intelectuais do IBESP dedicam grande atenção aos entraves reais e potenciais ao progresso. Nesta seção, a descrição dos três ismos que se combinam ao atraso moralismo, internacionalismo e populismo - entremeia-se à imaginação do futuro desejável. Isto é, a narrativa sobre o que não deve ser na política conjuga-se à postulação sobre o que deve ser na política. As formulações contranormativas não se dissociam, portanto, da positividade normativa. Muito pelo contrário, a força do seu enunciado é extraída justamente da ameaça que implicam ao cenário imaginado para a política. A narrativa sobre o indesejável esclarece e apura o entendimento sobre o desejável.

\section{As Classes Médias e o Moralismo}

O moralismo das camadas médias da população brasileira inaugura a sequência de lamentos que acompanha o exercício deontológico nos Cadernos. Segundo Jaguaribe, a classe média nasceu da urbanização, ainda em tempos do Império. Além das profissões liberais, os membros deste novo segmento também integraram os quadros militares e burocráticos do Estado. Ali teriam firmado o "clientelismo eleitoral" como solução de compromisso com os segmentos de latifundiários (Jaguaribe, 1953c:124). 
No editorial "O Golpe de Agosto", da terceira edição dos Cadernos, acusa-se o "parasitismo burocrático" da classe média e também sua incompreensão de fundo sobre o benefício particular e geral associado à necessária alteração da estrutura econômico-social do país. A inconsciência sobre seu lugar potencial a teria tornado "caudatária da burguesia mercantil", aliada aos interesses retrógrados da classe agrária. Isto significou que ela "perdeu, como classe, a possibilidade de produzir solução própria para o processo político-social brasileiro e passou a esperar oportunidades de inserção econômica do próprio capitalismo burguês" (autor não identificado, 1955b:6).

Os dirigentes dos estratos médios da sociedade, afastados de sua própria classe e acostumados aos altos escalões políticos, militares e financeiros, teriam se somado aos latifundiários na insatisfação com o lugar coadjuvante que ocupavam na política. Para Jaguaribe, a demanda destes segmentos por democracia, dirigida contra o Estado Novo de Getúlio Vargas, teria sido feita na esperança de "abrir, por via eleitoral, um acesso aos altos postos políticos e às fontes de financiamento". Anos depois, a classe média teria se convertido num dos principais elementos da tensão política que culminou no suicídio do presidente. Ela produziu, ressoou e propagou o discurso moralista (a "grande arma ideológica de luta contra Vargas") consagrado pela ascensão de Café Filho e reiterado à época do governo Juscelino Kubitscheck (Jaguaribe, 1953c:126).

O colaborador não identificado de "O Moralismo e a Alienação das Classes Médias, publicado no segundo volume dos Cadernos, corrobora esta perspectiva e identifica o moralismo como principal instrumento de ação política da UDN, criada contra o legado de Vargas à época da reabertura democrática. Segundo ele, a partir da lente moral, "tudo depende de os homens que dirigem os acontecimentos serem considerados bons ou maus". A vontade individual é então lida como "fundamento único do ser", soberana, indiferente e imune a todo condicionamento exterior (autor não identificado, 1954c:152). Trata-se, para o autor, de premissa insuficiente para a compreensão da política.

Embora os preceitos morais configurem expectativas políticas, a "campanha moralista", segundo seus críticos, teria como estrutura motivacional de fato o interesse mal compreendido da burguesia comercial, com ascendência sobre a pequena burguesia. Isto é, o setor da burguesia vinculado às trocas comerciais, movido por consideração imedia- 
tista, seduziria a pequena burguesia num movimento oposicionista superficial, descolado da compreensão do seu verdadeiro interesse. Ainda segundo o autor, "o moralismo reveste os sintomas da aparência de causa" e não contribui para uma reflexão consistente sobre as origens dos problemas nacionais. O moralismo teria a alienação como contraface necessária. E, como consequência, a reiteração de uma consciência equívoca sobre o interesse nacional.

Para o autor, a burguesia mercantil teria se colocado, como classe, contra o governo e teria levado adiante uma "estratégia de neutralização e desmoralização" que culminou no golpe branco dos coronéis e estaria caminhando para a deposição de Vargas (autor não identificado, 1954c:154). Objetivos de classe, realistas e imediatos, ganhavam temerariamente feição universalista.

Ao generalizar a "teoria da corrupção do Estado", o segmento mercantil liderava a demanda pela suspensão dos controles estatais sob a aparência de oportuna reivindicação moralista. Os operadores do moralismo desconheciam ou negligenciavam as raízes da corrupção no país, associadas ao subdesenvolvimento, às práticas de clientelismo e à espoliação econômica. De modo conveniente a seus propósitos de curto termo, produziam crítica superficial à cena da política e passavam ao largo das "causas e condições da inautenticidade do governo" (autor não identificado, 1954c:159). Atingiam o objeto da sua crítica - o governo - por um ângulo indesejável e desviavam a compreensão da política do seu bom curso.

Além dos setores médios udenistas, o "frisson moralista" também teria movido comunistas empenhados na crítica a Vargas. Fora dos quadros formais dos partidos, o Partido Comunista Brasileiro (PCB) teria pretendido "capitalizar em seu favor a agitação levada a efeito pela oposição moralista ao governo". Interessado em fragilizar o governo, o partido teria instruído seus comandados a "denunciarem os escândalos e a corrupção administrativos". Em seguida, teria se lançado em "aliança tácita" com a "imprensa popular e os órgãos da oposição moralista", apesar da "mútua hostilidade" que nutriam "em matéria de política internacional" (autor não identificado, 1954c:132).

Na cena política tomada pela crítica superficial, o antídoto do moralismo era o verdadeiro nacionalismo, imune, segundo seus idealizadores, às falsas consciências de classe. Os autores dos Cadernos não se descolam do seu principal eixo argumentativo: o interesse da nação. Alhe- 
ia às bases de reprodução do atraso, a retórica moralista despolitizava e simplificava a insatisfação: o protagonismo da cena pública deslocava-se para a vontade e ação individuais e, com tal movimento, corroborava a insensibilidade com relação às condições mais amplas de reprodução do infortúnio social. No Brasil, os Cadernos encerram valiosa - e quiçá pioneira - reação ao moralismo como teoria da política.

\section{Desvio Internacionalista: Udenistas, Comunistas e Intelectuais}

O surto moralista não esgotava o equívoco político capitaneado pela classe média. Entre os partidários da União Democrática Nacional (UDN), situados em grande medida nos estratos médios da população, o apreço desmedido pelo universo político econômico e cultural norte-americano não se somava ao interesse nacional. Muito pelo contrário, estabelecia-se em prejuízo dele.

No vício internacionalista, os udenistas se faziam curiosamente acompanhar dos comunistas, vinculados por laços de identidade e fidelidade alheios ao interesse nacional. No artigo "Três Etapas do Comunismo Brasileiro", de autor não identificado, acusa-se, entre os líderes do Partido Comunista (PC) brasileiro, a aversão por "qualquer teoria autêntica ou qualquer atividade autêntica do pensamento". Marcado pelo "estreito empirismo", combinação de "praticismo e ignorância teórica", o partido teria cerceado até mesmo a extraordinária capacidade política de Carlos Prestes, privado da fala direta ao povo e sempre mediado pela Comissão Executiva do Comitê Nacional. O líder político teria saído da prisão física para a "clausura intelectual" (autor não identificado, 1954f:133).

À diferença de outras experiências nacionais do comunismo, haveria entre os comunistas brasileiros baixa "vitalidade intelectual" e "consciência dos seus próprios problemas". A subserviência do partido às "conveniências estratégicas e táticas da URSS" significaria perigosa oscilação entre linhas políticas tão diversas quanto o "terrorismo anarquista" e o "franco oportunismo de direita". A menos que suas "deficiências" fossem "sanadas", o partido seguiria produzindo "pesado ônus para as forças que lutam de maneira autônoma pelo desenvolvimento nacional" (autor não identificado, 1954f:135).

Além da expressão partidária, com implicações políticas mais evidentes, o vício internacionalista também teria ganhado forma, segundo Guerreiro Ramos, na visão turva de intelectuais brasileiros sobre a na- 
ção. Em três artigos clássicos publicados nos Cadernos - "O Problema do Negro na Sociologia Brasileira" (1955), "A Ideologia da Jeunesse Dorée" (1955) e "O Inconsciente Sociológico" (1956) - Ramos disserta sobre os estudos e as práticas intelectuais em curso a partir de um instrumento de juízo: a vocação nacionalista. Num cenário geral de desalento, aponta bons exemplos em gerações passadas.

Em "O Problema do Negro na Sociologia Brasileira", o argumento central do autor gira em torno da noção de uma ciência nacional, autêntica. O problema do negro importa para Ramos como tema que precipita manifestações de nacionalismo ou alienação, e não como tema em si. Neste artigo, o autor produz uma espécie de panorama dos pensadores brasileiros que se dedicaram à questão racial. A única distinção relevante apontada é entre cientistas e copistas - isto é, entre autores com sensibilidade para interpretar a especificidade das questões nacionais, de um lado, e "beatos da ciência importada", de outro (Ramos, s.d:52).

No primeiro grupo, de autênticos, estariam Silvio Romero, Euclides da Cunha, Alberto Torres e Oliveira Vianna. Entre eles, argumenta Ramos (s.d), Torres manifestou incômodo explícito com o conceito de raça, dada sua inspiração em sistemas mentais de outros países, e Silvio Romero fugiu ao essencialismo da ideia e assinalou a necessidade de considerar "múltiplos aspectos" da sociedade brasileira para interpretar a condição particular do negro nela. Quanto a Euclides da Cunha e Oliveira Vianna, compartilharam os termos da antropologia racista de seu tempo e tomaram negros e mestiços por tipos inferiores. A despeito disto, a virtude teria superado o equívoco: ambos contribuíram para a "corrente autonomista de nosso pensamento sociológico". Sobre Oliveira Vianna, ressalva: "mesmo errando ao focalizar o tema da raça soube vencer a tentação de tratar o negro no Brasil como um elemento exótico e petrificado. Tratou-o como brasileiro" (Ramos, s.d:50). Como desagravo aos erros, além da vocação nacional, Ramos assinala a reversibilidade do desvio racialista. Na sua perspectiva, todas as variáveis do trabalho científico subordinam-se ao elemento primordial do nacionalismo.

Nina Rodrigues, por contraste, figura na sua narrativa como contraexemplo do intelectual. Para ele, o negro teria instalado uma "espécie de lesão definitiva" (Ramos, s.d:50) na sociedade. Diferente de Euclides da Cunha e Silvio Romero, que assumiram uma "atitude indutiva" face ao meio brasileiro, Nina Rodrigues não soube desconfiar "da soci- 
ologia e da antropologia de importação". Com relação a autores estrangeiros, teria manifestado "êxtase e pacholice". Não haveria, na sua geração, exemplo de tamanha "basbaquice e ingenuidade": sua obra seria um "monumento de asneiras" (Ramos:s.d:52-54).

Além do antropólogo maranhense, também Artur Ramos e Gilberto Freire seriam reféns de uma abordagem estática da questão racial. Entre os "mais recentes": Donald Pierson, Charles Wagley, Florestan Fernandes e Thales de Azevedo, todos operadores de um pensamento "alienado" e de uma "ideologia de brancura ou de claridade".

O perfil dos intelectuais indesejados é ainda objeto de "A Ideologia da Jeunesse Dorée". Neste texto, Guerreiro Ramos produz crítica veemente à geração de homens "bem nascidos", alheia à "exigência de concreção do pensamento" e inebriada pelo esteticismo das formas retóricas. $\mathrm{O}$ autor refere-se nominalmente a Alceu Amoroso Lima, Afonso Arinos de Melo Franco e Otávio de Faria. Enfeixados numa posição "acadêmico-normativa", os intelectuais dorée descartam o mundo real e desprezam o povo como sujeito da política (Ramos, 1955:102). No seu exercício demofóbico, tomam "o estádio transitório da psicologia coletiva como definitivo" e reduzem o "problema político a um problema moral", passível de ajuste pelas elites e pelos intelectuais. Conservadores, repudiam a revolução como instrumento de transformação social e tomam os anos 30 no país por um período de "indisciplina mental e desordem intelectual" (Ramos,1955:111).

Por fim, a crítica ao subjetivismo dorée é ainda reiterada em "Inconsciente Sociológico", na forma do elogio a Azevedo Amaral, Virgínio Santa Rosa e Martins de Almeida, intelectuais afeitos ao "caminho empírico-indutivo", embora reféns dos "equívocos da ciência oficial da época". Mais uma vez, desde que não ofusquem a vocação nacional, os "grosseiros erros de observação" são referidos ao contexto e minimizados (Ramos, 1956:226). A confusão entre condição e natureza, a falta de uma "teoria social orgânica", o "intuitivismo" e, mais uma vez, o "tributo" ao racismo e ao "biologismo" não ameaçam a contribuição dos autores nominados para a "teoria social brasileira que vem se formando por acumulação", inaugurada por João Ribeiro, Silvio Romero, Euclides da Cunha e Alberto Torres (Ramos, 1956:226).

Tal como em "O Problema do Negro na Sociedade Brasileira" e "A Ideologia da Jeunesse Dorée", a sensibilidade para as condições específicas da sociedade brasileira é o princípio por excelência de validação 
científica para Ramos. É da afinidade dos autores com a realidade nacional que ele infere a legitimidade dos seus critérios de pensamento e ação. Trata-se de elemento que condiciona o comportamento científico. A nação constitui, portanto, lente necessária da ciência, compreendida menos pela pertinência das premissas universais do que pela capacidade de elucidação do particular. No texto de Ramos, o nacionalismo extrapola as fronteiras da política e se instala na imaginação da ciência. Se não suspensos, os limites entre uma e outra perdem nitidez. Embora afinado com o tom mais geral dos Cadernos, o autor distingue-se pelo radicalismo da formulação nacionalista, motivo central do rompimento futuro com Hélio Jaguaribe e característica marcante da cena política nacional nos anos que antecederam o golpe militar.

\section{Populismo}

Além do moralismo e das manifestações várias do internacionalismo, os Cadernos elencam ainda um terceiro operador de inconsciência nacional: o populismo. No segundo número da revista, o tema foi abordado a partir da crítica a Ademar de Barros, sob o impacto da notável expressão que o político havia alcançado no contexto paulista, associando voto urbano e rural. Segundo o autor de "Que É o Ademarismo?", Ademar de Barros não dependia da mediação dos chefes locais, tal como o esquema clássico que atendia aos interesses dos chefes estaduais do PSD. O político também se beneficiava dos recursos típicos da política de clientela, mas sua influência sobre o eleitorado rural de base era direta. Por meio de "ideologia primária e infusa" e "verborragia pseudo-social" (autor não identificado, 1954d:141), seduzia o eleitor do campo e também da cidade, o que incluía proletariado e setores da pequena burguesia.

Em sintonia com o propósito de consolidar o capitalismo mercantil, o ademarismo era retrógrado, lesivo ao interesse nacional. Por sua face popular, era confundido com fenômenos políticos de esquerda, leitura apressada que chegou a inspirar apoio dos comunistas. Na contramão deste equívoco, o autor afirma não existirem laços necessários entre a composição social de um grupo político e sua filiação ideológica. A influência marxista no imaginário político seria responsável pela associação inoportuna entre progressismo e povo, reacionarismo e elites.

Esta perspectiva turvaria a distinção essencial entre grupos de esquerda, vinculados à consciência e vontade de superação das estruturas de 
dominação, e movimentos de massa, "expressão confusa e primária de aspirações instintivas" perfeitamente integrada às relações de exploração em curso. De acordo com o autor, "a massa é conglomerado multitudinário de indivíduos, (...) é o produto final da espoliação de clas-

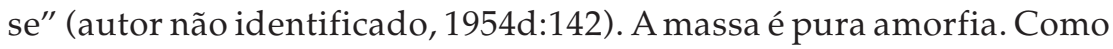
tal, é facilmente instrumentalizada: não pode ser sujeito da política, mas apenas objeto a serviço de interesses de poder. Distingue-se essencialmente do proletariado por faltar-lhe consciência de classe.

Nesta perspectiva, os homens que sofreram o fenômeno de massificação da política representariam um tipo psicossocial: o homem-massa. O autor atenta então para a possibilidade deste tipo expandir-se a ponto de extrapolar as fronteiras das massas e constituir o "protótipo humano de toda comunidade" (autor não identificado, 1954d:142), momento em que a massificação alcança um segundo nível e mobiliza as classes dominantes.

O ademarismo seria expressão brasileira da massificação em primeiro estágio, resultado da combinação de três condições: a inconsciência de segmentos expressivos da sociedade a respeito do lugar inferior que ocupam na estrutura de dominação social, a ineficiência da classe dirigente e, por fim, a existência de um líder carismático. Não haveria ineditismo, contudo, nesta experiência da política. Nos Estados Unidos, foi McCarthy quem extraiu proveito das condições para ascensão do populismo.

Na genealogia nacional do populismo, o autor chama atenção para a correlação significativa entre formações urbanas e massificação. A partir dos anos 30, o recrutamento de camponeses para compor os quadros da indústria em formação lançou nas cidades um exército de trabalhadores com baixas possibilidades de alcançar consciência de sua condição de classe. Este desenho original da cena industrial urbana acomodou-se sem grande tensão a um processo de sindicalização iniciado pelo Estado, esvaziado de iniciativa popular. Quinze anos depois, apesar de um e outro sinal de amadurecimento cívico, os homens da cidade seguiam vulneráveis a movimentos como o ademarismo.

Ao imaginar o futuro da nação a partir da sensibilidade para a questão do populismo, o autor postula dois cenários possíveis: um positivo e outro negativo. O primeiro deles é o da formação de uma "ampla frente nacional democrática de esquerda", constituída pela burguesia industrial, pelos "setores esclarecidos da classe média e pela parcela politi- 
zada do proletariado", capaz de contornar os desvios do interesse primordial, o interesse nacional. O outro cenário, prejudicial ao desenvolvimento econômico e social do país, é o de intervenção do Exército com apoio do segmento superior da classe média, dos latifundiários remanescentes e do extrato da "burguesia mercantil contrário ao ademarismo" em razão da suposição equívoca de seu alinhamento "de esquerda" (autor não identificado, 1954d:145). Mais uma vez, observa-se, na taxonomia dos Cadernos, a polarização entre forças progressistas e retrógradas, respectivamente alinhadas e desalinhadas com o interesse nacional.

Sem desvios demofóbicos, o autor dedicado ao tema do ademarismo atenta para uma condição frágil do povo, incapaz de autonomia política. O objeto da crítica à simplificação do processo político não é constituído apenas, contudo, pelos baixos extratos sociais urbano e rural, presas fáceis das estratégias retóricas e de ação do populismo. Ela se dirige de forma mais contundente aos setores em condições de maior esclarecimento político que corroboram o equívoco populista e aderem a ele até mesmo de modo entusiasmado, inebriados, genuinamente ou não, por uma suposta essência popular. Nesta perspectiva, a política, esvaziada de romantismo em relação ao povo, não prescinde dele. Não há autossuficiência suposta em nenhum segmento da populaçãopovo, burguesias ou intelectuais. A direção do progresso supõe um princípio fundamental de complementaridade entre as partes implicadas, consubstanciado, para voltar ao argumento central, pela boa consciência do interesse nacional. Trata-se de valioso exercício de esclarecimento sobre o estado da arte da política, com equilíbrio nas expectativas e atribuição de responsabilidades aos diferentes personagens sociais.

\section{VARGAS E 0 VARGUISMO: A PEDAGOGIA DO SUICÍDIO}

A época das edições dos Cadernos viveu convulsionada pela ameaça do golpe. A relativa normalidade da cena institucional conviveu com a incerteza sobre o futuro político próximo. Os intelectuais do IBESP dedicaram-se, entre tantos outros temas, à ideia de uma política vivida em suspenso, com baixa institucionalidade e alta imprevisibilidade. Nesta cena, a expectativa do golpe figura tragicamente no horizonte da política, mas não esgota suas possibilidades. O tom mais geral dos Cadernos aponta para a existência de sinais ainda tímidos - embora potentes - de renovação nacional pela estabilização da democracia. 
Curiosamente, o artigo sobre ademarismo não menciona Getúlio Vargas, protagonista da política nacional marcado pelo estigma do populismo. O tratamento dos Cadernos a Vargas é ambíguo, como seria ambígua, para seus autores, sua política, oscilante entre "tendências de autodeterminação do país" e articulação com "grupos internacionais" que se beneficiam da "exportação de gêneros alimentícios e matérias-primas em troca de produtos acabados e semi-acabados" (autor não identificado, 1955c:49) ${ }^{13}$. Os autores tendem a um tom crítico contra Vargas, atribuindo-lhe práticas de "indigência ideológica" e "maquiavelismo psicológico" (autor não identificado, 1955b:13) contra os trabalhadores, mas não raro ponderam os prós e contras dos seus modos de fazer política ${ }^{14}$ e, ainda, em alguns momentos, chegam a identificar na sua direção da política um importante impulso para a condição moderna.

A inflexão dos Cadernos no tratamento sobre o getulismo aconteceu na altura do suicídio do líder político, evento que repercutiu "profunda e subitamente nas massas operárias". Para o autor de artigo intitulado "O Golpe de Agosto", que inicia o terceiro volume dos Cadernos, a carta-testamento teria produzido uma "iluminação emocional na consciência do proletariado, fazendo-o compreender que o móvel real da luta contra Vargas e do golpe que o havia deposto era o interesse de classe das forças reacionárias e antinacionais" (autor não identificado, 1955b:19).

Nesta visão, a brusca saída de cena do personagem que então pautava o debate público, objeto de adesão ou crítica veemente, teria tido o efeito de um amadurecimento por choque. Na nova condição, o getulismo converte-se numa "pré-ideologia" potencial. Entenda-se por isso sua capacidade de atender, "nas condições concretas do Brasil, aos interesses dialeticamente solidários do proletariado, da intelligentsia técnica e da burguesia industrial", ajustando-se ao interesse nacional, embora sem "fundamentação teórica" (autor não identificado, 1955b:20).

Em certa medida, portanto, o conteúdo da política varguista separa-se de seu suporte físico, humano, e passa a constituir um modelo do fazer político, despersonalizado. Passa-se então a distinguir getulismo histórico, associado à figura de Vargas, de getulismo ideológico, desassociado dela. O segundo nasce do primeiro e mantém com ele tensa relação. 
Em artigo intitulado "Sentido e Perspectivas do Governo JK", o autor não identificado (1956), atento ao "momento de revelação do sentido do getulismo", enxerga estimulante novidade no quadro político-partidário: a "tendência indiscutível do PSD e do PTB" a se tornarem "autênticos partidos, conscientes da necessidade de assegurar a organicidade da sua representação". Transitava-se, enfim, de uma situação de formalismo ou artificialismo partidário para uma cena consistente, bem estruturada em torno das consciências de classe. Os partidos políticos deixavam de ser uma realidade sazonal, vinculada aos calendários eleitorais, e se tornavam mais sólidos. À diferença dos governos Dutra e Vargas, quando a maioria governamental, sob influência dos "grupos de pressão" (autor não identificado, 1956c:3), exilou-se de suas bases eleitorais, a nova realidade política parecia pautar-se em vínculos mais consistentes entre representantes e representados. A democracia, enfim, dava sinais de amadurecimento.

Para o autor, Juscelino Kubitscheck fez-se herdeiro de um "getulismo programático", ideológico. O juscelinismo, em medida significativa, consistiria numa mutação pragmática do getulismo, convertido em ideologia do desenvolvimento. JK teria compreendido em tempo a necessidade de superação da "capilaridade ideológica das classes interessadas na conservação do esquema vigente de exploração" (autor não identificado, 1956c:6)

Para Vargas, a consciência da "oposição profunda entre as forças do desenvolvimento e o sistema econômico tradicional" ganhou a forma de tragédia pessoal (ibidem). A narrativa dos Cadernos sobre o efeito político deste episódio não expande o sentido do trágico, entretanto, para além desta chave pessoal. Muito pelo contrário, o infortúnio de Vargas parece mesmo constituir a condição de possibilidade de uma boa fortuna pública. O suicídio libertou o getulismo de Getúlio e instituiu sua conversão potencial em ideologia do desenvolvimento nacional. A perspectiva dos Cadernos faz transparecer uma certa pedagogia pública do suicídio, isto é, a suposição de que a tragédia pessoal de Vargas amadureceu e fez precipitar, entre as classes dominadas, uma consciência mais fiel à configuração de fato das forças sociais.

A experiência do varguismo extrapolava, portanto, a consideração do personagem e constituía-se como força da política que dava sinais de autonomização em relação à sua origem. Em março de 1956, os colaboradores dos Cadernos tinham a expectativa de uma inflexão próxima na 
cena pública. O sentido de encruzilhada parecia instalado em expressão limite. Embora cogitassem um desdobramento político positivo do legado de Vargas, grave incerteza pairava sobre seu destino.

Dois percursos possíveis, de ruptura ou permanência, anunciavam-se como possibilidade para o getulismo: seguir em trajetória virtuosa como alternativa à "atual alienação" da burguesia industrial e da intelligentsia técnica, ainda sob a esfera de influência dos interesses latifúndio-mercantis, ou "confundir-se com uma das muitas versões do populismo demagógico, de tipo ademaresco, conduzindo o país para uma solução primária e brutal" (autor não identificado, 1955b:22). Mais uma vez, as forças do atraso figuram como ameaça ao progresso, forma por excelência do verdadeiro interesse nacional.

\section{NOTAS FINAIS}

Ao longo dos Cadernos, otimismo e normatividade confundem-se e compõem o argumento do interesse nacional. A imaginação sobre o devir tende a ser positiva. Apesar disso, prevalece o sentido de um tempo encruzilhada, vivido em suspenso, sem sinais evidentes de desfecho. As forças do atraso perderam a vitalidade de outros tempos, mas ainda configuravam o ambiente político a seu modo. Não havia clareza sobre o futuro.

Em ensaio sobre a sucessão presidencial, publicado no quarto volume dos Cadernos, em agosto de 1955, lê-se: "o Brasil se defronta com uma opção fatal: ou completa seu desenvolvimento econômico ou retrocede à condição de país colonial e se constitui, definitivamente, em satélite econômico dos Estados Unidos" (autor não identificado, 1955b:4). A transição em curso corria o risco da estagnação. Segundo autor de estudo sobre a política de desenvolvimento, o Brasil poderia estancar num "semicolonialismo mercantilista, a exemplo do que ocorreu em diversos países da América Latina (Peru, Venezuela), do Oriente Próximo (Arábia Saudita, Irã) e do Oriente Remoto (Paquistão, Ceilão)" (autor não identificado, 1956b:138).

O progresso esbarrava no entrave econômico e também na democracia incipiente. Durante o tempo de vida dos Cadernos, a ameaça permanente do golpe instalava a dúvida sobre o futuro, embora não tivesse consistência formal e não colidisse explicitamente com as rotinas institucionais do regime em curso. A sensação de iminência do golpe seria, por si só, uma forma de golpe, um ruído ao andamento regular da política. 
Os sentidos de cooperação e equilíbrio, imprescindíveis para o desenvolvimento nacional, só poderiam se instalar num ambiente de permanência. A indefinição e a ameaça tendiam a estancar o processo político num compasso de espera agônico.

Além do entendimento mais direto e estreito da democracia, vinculado à garantia do voto, o paradigma democrático também - e fundamentalmente - implicaria em renovação do princípio de funcionamento das instituições. Em artigo publicado em 1956 sem autoria identificada, mas muito possivelmente assinado por Hélio Jaguaribe, comenta-se a necessidade de superar o Estado Cartorial, impregnado de "funcionalidade aparente" e de fato destinado à "política de clientela", e alcançar a forma moderna do Estado Serviço, comprometido com a "prestação de serviço público". Em alusão à experiência política do varguismo, o autor afirma que, apesar de a "maquinaria cartorial" já ter se confrontado com "novas forças e novas relações sociais", que "escaparam às possibilidades de manipulação por via meramente clientelística", não chegou a ser desmontada e tinha perigosa sobrevida no cotidiano da política (autor não identificado, 1956b:136).

Para o autor, a iniciativa do progresso não se esgota, entretanto, nos quadros do Estado: o princípio móvel do progresso distribui-se, não sem tensão e ambiguidade, entre política e sociologia, entre vontade e contingência. Em "A Crise do Nosso Tempo e do Brasil", também possivelmente de Jaguaribe, afirma-se a pertinência da "autoconsciência histórica" do século XIX, pautado na suposição de que "é preciso compreender o mundo para nele operar eficazmente". Ao mesmo tempo, recusa o moralismo como solução para contextos de crise. Nesta perspectiva, o homem é tido como "sujeito e objeto de si mesmo e da história" e descrito, simultaneamente, como "livre e condicionado" (autor não identificado, 1954a:2).

A teoria da ideologia presente nos Cadernos, afinada com essa condição humana afirmada por Jaguaribe, supõe atos de inteligência e vontade como móveis da ação, ao mesmo tempo em que os vincula a "condições objetivas de possibilidade". O exagero da primeira premissa constitui as bases do voluntarismo político e também da crítica moralista, ambos improfícuos. O exagero da segunda, isto é, o excesso de evocação da realidade, esvazia a validade da iniciativa dos homens e vincula o destino exclusivamente à circunstância. À diferença destas duas situações-limite, a "pauta de valores" implicada na ideologia deve articu- 
lar-se com um "projeto social dotado de eficácia histórica" (Jaguaribe, 1953c:137). Trata-se de um idealismo orgânico, afinado com as reais possibilidades de desenvolvimento social. Os operadores da ideologiabem como os homens em geral - não dispõem de "liberdade incondicionada", mas tampouco são objeto de um "processo natural", definido a priori (autor não identificado, 1954a:2).

Imaginação e circunstância compõem, portanto, o espectro intelectual dos autores-editores dos Cadernos. E mesmo o nacionalismo é validado pelos ajustes às considerações de oportunidade. Em "Política do Petróleo", Heitor Lima Rocha avalia que a demanda por "autossuficiência do país em combustíveis líquidos", apesar de justificável, não deve "constituir uma intenção política e muito menos um objetivo de curto prazo", dado seu forte irrealismo e sua relevância marginal na responsabilidade pelo atraso brasileiro (Rocha, 1955:39). O nacionalismo, quando bem compreendido, não ofusca o interesse nacional. O mesmo princípio orienta a interpretação de que o "comércio com o Leste" constitui questão "econômica e estratégica" (ibidem:57) e a intervenção do Estado, imposição das exigências do desenvolvimento.

Numa cena internacional polarizada, a maturação do paradigma nacional não poderia resultar da adesão a um dos modelos em disputa. Os desafios político e sociológico implicados na transição para o progresso envolviam justamente a composição de um cenário político próprio, avesso a imposições estrangeiras. Consideradas as condições específicas do desenvolvimento no país, o adensamento da presença do Estado na política e na economia não constituía ameaça socialista, mas medida oportuna ${ }^{15}$.

Legadas a si próprias, em estado ainda imaturo de desenvolvimento das consciências, as forças progressistas poderiam sucumbir ao legado cartorialista e deixar imprimir no futuro as marcas do passado. O triunfo do interesse nacional nasceria da delicada simbiose entre consciência social e direção política.

(Recebido para publicação em março de 2012)

(Reapresentado em junho de 2012)

(Aprovado para publicação em agosto de 2012) 


\section{NOTAS}

1. As cinco edições dos Cadernos do Nosso Tempo estão publicadas no volume 4 da Revista Estudos Políticos, disponível em http:/ / www.revistaestudospoliticos.com.

2. A noção de idioma nacionalista é proposta por Francisco Weffort e retomada por Daniel Pécaut (1990).

3. Fundado no Rio de Janeiro, em 1953, o IBESP foi herdeiro de experiências anteriores de reflexão sobre a sociedade e a política nacionais. Em 1947, jovens intelectuais dedicados ao debate sobre as possibilidades de desenvolvimento para o país assinavam uma coluna na quinta página do Jornal do Comércio com o objetivo de refletir sobre problemas especificamente brasileiros. Em 1952, o grupo reunia intelectuais de São Paulo e do Rio de Janeiro e passou a encontrar-se periodicamente no Parque Nacional de Itatiaia, a meio caminho das duas capitais. O grupo de Itatiaia, como ficou conhecido, buscou, sem sucesso, vinculação ao governo Vargas. A intenção de assessorar o governo era compartilhada pelo segmento carioca do grupo, interessado na tradução política e institucional de sua reflexão sobre os caminhos para o desenvolvimento nacional. À diferença dos paulistas, mais dedicados a questões de ordem filosófica, os cariocas aproximavam-se pela afinidade com temas da política. Embora esta distinção não tenha inibido a aproximação original num projeto único, marcou a dispersão do grupo pouco depois de sua criação. No ano seguinte à sua formação, os intelectuais do Rio de Janeiro, acompanhados por Roland Corbisier, desertor do grupo paulista, criaram então o IBESP. A despeito das dificuldades de sobrevida material, o IBESP manteve intensas atividades intelectual e editorial.

4. Notar que o Instituto Superior de Estudos Brasileiros (ISEB), criado em 1955, deu seguimento ao IBESP em nova forma institucional, vinculada ao Ministério da Educação e Cultura. Mesmo depois desta transformação, as edições dos Cadernos do Nosso Tempo seguiram referidas ao extinto IBESP.

5. Ainda a respeito de bibliografia inspirada exclusivamente na experiência do IBESP e dos Cadernos, vale notar também artigo de Bariani (2005), dedicado à descrição das origens e de temas-chave do Instituto.

6. Parte significativa dos artigos dos Cadernos não tem autoria identificada. Este tema será tratado logo adiante.

7. Ao longo das cinco edições dos Cadernos, o conselho de redação teve alterações, mas basicamente incluiu: Candido Antonio Mendes de Almeida, Carlos Luz de Andrade, Averardo Moreira Lima, Exaldo Correia Lima, Fábio Breves, Guerreiro Ramos, Heitor Lima Rocha, Hélio Jaguaribe, Ignacio Rangel, Israel Klabin, José Ribeiro de Lira, Osório Gomes, Moacir Felix de Oliveira, Nelson Werneck Sodré, Oscar Lourenzo Fernandez, Ottolmy Strauch, Roland Corbisier, Romulo Almeida.

8. Este é o caso de todos os textos que compõem o terceiro número dos Cadernos e também de artigos esparsos nas demais edições.

9. Embora a autoria do artigo referido não seja identificada, pode-se com alguma segurança atribuí-la a Hélio Jaguaribe.

10. Sobre a querela entre Hélio Jaguaribe e Guerreiro Ramos, que cindiu o ISEB e instituiu uma nova fase do Instituto, ver: Abreu, 1979; Jaguaribe, 1979; Sodré, 1978. 
11. Para reflexão sobre a vocação dos intelectuais como elite dirigente e os fundamentos da legitimidade do seu poder, ver a primeira parte da obra referida: Intelectuais e a Política no Brasil.

12. A presença do lusitanismo na formação nacional é também brevemente comentada por Hélio Jaguaribe em "A Crise Brasileira". Para ele, herdamos a cultura portuguesa atingida pela crise da Reforma, "imobilizada em suas ideias medievais", sem "instrumentos para compreensão do mundo "moderno" (Jaguaribe, 1953c:129).

13. Ainda sobre a ambiguidade referida, vale citar: "Vargas sempre formulou seu programa de maneira assistemática, híbrida" e "em meio a teses que se contradiziam". Mas, "a despeito de tais claudicâncias e da insuficiente coerência de suas posições, Vargas, em última instância, representa em nossa evolução partidária a mais avançada posição a que atingiu, entre nós, a política paternalista ou de clientela. Todavia, Vargas jamais teve uma concepção elaborada, em termos ideológicos, da tarefa governamental. O cidadão Vargas era, em sua vida privada, um proprietário de fazenda, e esta condição teria forçosamente de influenciar a sua concepção de governar, principalmente não tendo sido ele um homem dado a cogitações teóricas" (autor não identificado, 1955c:50).

14. A este propósito, cabe citar, por exemplo, fragmento do mesmo artigo de autor não identificado: "em seu governo [referência ao governo Vargas] jamais obedeceu a uma diretriz política firme, mas se mostrava plástico às forças reais em jogo, procurando sempre uma posição de equilíbrio" (autor não identificado, 1955c:50).

15. Esta ideia está bem ilustrada em fragmento do estudo "Para uma Política nacional do desenvolvimento", lê-se: "depois da depressão, os Estados Unidos passaram a planejar certos setores de sua economia, submetendo-se à ação corretiva do Estado. Cabe distinguir, por isso, planejamento de socialismo e ambos de totalitarismo e ditadura. O fascismo italiano e o falangismo espanhol, sob regimes ditatoriais e totalizantes, não submetem suas economias a nenhum planejamento de conjunto" (autor não identificado, 1956b:106). 


\section{REFERÊNCIAS BIBLIOGRÁFICAS}

ABREU, Alzira Alves de. (1979), Nationalisme et Action Politique au Brésil: Une Étude sur l'ISEB. Paris, thèse, Université René Descartes.

AUTOR NÃO IDENTIFICADO. (1953), "Apresentação". Cadernos do Nosso Tempo, no 1, outubro-dezembro, pp. 1-2.

. (1954a), “A Crise do Nosso Tempo e do Brasil”. Cadernos do Nosso Tempo, no 2, janeiro-junho, pp. 1-17.

. (1954b), “A Denúncia João Neves". Cadernos do Nosso Tempo, no 2, janeiro-junho, pp. 83-100.

. (1954c), “O Moralismo e a Alienação das Classes Médias". Cadernos do Nosso Tempo, no 2, janeiro-junho, pp. 150-159.

. (1954d), O Que é o Ademarismo?". Cadernos do Nosso Tempo, no 2, janeiro-junho, pp. 129-149.

. (1954e), "Situação Política Brasileira". Cadernos do Nosso Tempo, no 2, janeiro-junho, pp. 101-122.

. (1954f), "Três Etapas do Comunismo Brasileiro". Cadernos do Nosso Tempo, no 2, janeiro-junho, pp. 123-138.

. (1955a), "As Eleições de Outubro". Cadernos do Nosso Tempo, no 3, janeiro-março, pp. 31-48.

. (1955b), "O Golpe de Agosto". Cadernos do Nosso Tempo, no 3, janeiro-março, pp. $1-22$.

. (1955c), "O Legado Político de Vargas e as Possibilidades de sua Potencialização Ideológica". Cadernos do Nosso Tempo, no 3, janeiro-março, pp. 49-51.

. (1956a), "Golpe e Antigolpe na Presente Situação Brasileira". Cadernos do Nosso Tempo, no 5, janeiro-março, pp. 189-200.

. (1956b), "Para uma Política Nacional de Desenvolvimento". Cadernos do Nosso Tempo, no 5, janeiro-março, pp. 47-180.

. (1956c), "Sentido e Perspectiva do Governo Kubitschek". Cadernos do Nosso Tempo, no 5, janeiro-março, pp. 1-18.

BARIANI, Edson. (2005), “Uma Intelligensia Nacional: Grupo de Itatiaia, IBESP e os Cadernos do Nosso Tempo". Caderno CRH, vol. 18, no 44, pp. 249-256.

FERNANDEZ, Oscar Lorenzo. (1955), "Análise Existencial da Realidade Brasileira". Cadernos do Nosso Tempo, no 4, abril-agosto, 1955, pp. 118-163.

FERREIRA, Jorge. (2001), “Introdução; O Nome e a Coisa: O Populismo na Política Brasileira", in J. Ferreira (org.), O Populismo e sua História: Debate e Crítica. Rio de Janeiro, Civilização Brasileira, pp. 7-16; 59-124.

GOMES, Ângela de Castro. (2001), “O Populismo e as Ciências Sociais no Brasil: Notas sobre a Trajetória de um Conceito", in J. Ferreira (org.), O Populismo e sua História: Debate e Crítica. Rio de Janeiro, Civilização Brasileira, pp. 17-53. 
JAGUARIBE, Hélio. (1979), “ISEB, um Breve Depoimento e uma Reapreciação Crítica”. Cadernos de Opinião, no 14, pp. 94-110.

. (1953a), "A Crise Ministerial e a Nova Política do Sr. Getúlio Vargas". Cadernos do Nosso Tempo, no 1, outubro-dezembro, pp. 90-98.

. (1953b), "A Eleição do Sr. Jânio Quadros". Cadernos do Nosso Tempo, no 1, outubro-dezembro, pp. 99-102.

. (1953c), “A Crise Brasileira". Cadernos do Nosso Tempo, no 1, outubro-dezembro, pp. 120-160.

PÉCAUT, Daniel. (1989), Entrele Peuple et la Nation: Les Intellectuels et la Politique au Brésil. Paris, Ed. de la Maison des Sciences de l'Homme. (1990), Intelectuais e a Política no Brasil. São Paulo, Editora Ática.

RAMOS, Guerreiro. (1955), "A Ideologia da Jeunesse Dorée". Cadernos do Nosso Tempo, no 4, abril-agosto, pp. 101-112.

. (1956), "O Inconsciente Sociológico". Cadernos do Nosso Tempo, no 5, janeiro-março 1956, pp. 225-236.

. (s/d), "O Problema no Negro na Sociedade Brasileira", in S. Schwartzman (org.), O Pensamento Nacionalista e os "Cadernos do Nosso Tempo". Brasília, UnB, Câmara dos Deputados, pp. 39-69.

ROCHA, Heitor Lima. (1955), "Política do Petróleo". Cadernos do Nosso Tempo, no 4, p. 39.

SCHWARTZMAN, Simon. (s/d), "Introdução", in S. Schwartzman (org.), O Pensamento Nacionalista e os "Cadernos do Nosso Tempo". Brasília, UnB, Câmara dos Deputados, pp. 3-6.

SODRÉ, Nelson Werneck. (1978), A Verdade sobre o ISEB. Rio de Janeiro, Avenir Editora. 


\section{ABSTRACT \\ Cadernos do Nosso Tempo and the National Interest}

The aim of this article was to investigate how Brazil's national interest was interpreted by authors and editors of Cadernos do Nosso Tempo [Reports of Our Time], published by the Brazilian Institute of Economics, Sociology, and Politics (IBESP) from December 1953 to March 1956. Based on a systematic reading of Cadernos and the related bibliographic references, the author discusses the understandings of the political state-of-the-art, the nation's potential development, the obstacles to such development, and Getúlio Vargas' political legacy. According to IBESP intellectuals, nationalism constituted the only means for overcoming fragmented political experience.

Key words: national development; nationalism; Getúlio Vargas; IBESP; Cadernos do Nosso Tempo

\section{RÉSUMÉ}

\section{Les Cadernos do Nosso Tempo et l'Intérêt National}

Cet article a pour but de rechercher et de mettre à jour l'intérêt national des auteurs-éditeurs des Cadernos do Nosso Tempo édités par l'Instituto Brasileiro de Economia, Sociologia e Política (IBESP) entre décembre 1953 et mars 1956. A partir de la lecture systématique des Cadernos et d'une bibliographie pertinente, l'auteur traite des compréhensions dont il est question sur le bilan de la politique, le développement potentiel de la nation, ses entraves et, finalement, le legs politique de Getúlio Vargas. Pour les intellectuels do l'IBESP, le nationalisme bien compris est le Seul moyen permettant de surmonter l'expérience politique fragmentaire.

Mots-clé: développement national; nationalisme; Getúlio Vargas, IBESP; Cadernos do Nosso Tempo 